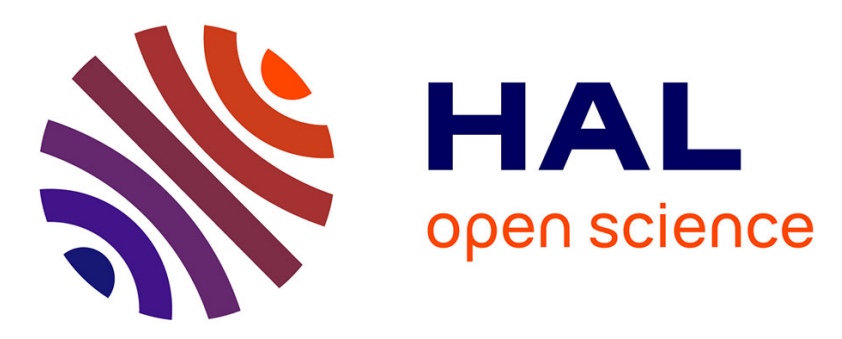

\title{
Time-dependent behaviour of hardened cement paste under isotropic loading
}

Vu Manh-Huyen, Jean Sulem, Siavash Ghabezloo, Laudet Jean-Benoît, Garnier André, Sylvine Guédon

\section{- To cite this version:}

Vu Manh-Huyen, Jean Sulem, Siavash Ghabezloo, Laudet Jean-Benoît, Garnier André, et al.. Timedependent behaviour of hardened cement paste under isotropic loading. Cement and Concrete Research, 2012, in press. 10.1016/j.cemconres.2012.03.002 . hal-00689716

\section{HAL Id: hal-00689716 https://hal.science/hal-00689716}

Submitted on 19 Apr 2012

HAL is a multi-disciplinary open access archive for the deposit and dissemination of scientific research documents, whether they are published or not. The documents may come from teaching and research institutions in France or abroad, or from public or private research centers.
L'archive ouverte pluridisciplinaire HAL, est destinée au dépôt et à la diffusion de documents scientifiques de niveau recherche, publiés ou non, émanant des établissements d'enseignement et de recherche français ou étrangers, des laboratoires publics ou privés. 


\title{
Time-dependent behaviour of hardened cement paste under isotropic loading
}

\author{
Manh-Huyen $\mathrm{Vu}^{1,2}$, Jean Sulem ${ }^{1}$, Siavash Ghabezloo ${ }^{1}$, Jean-Benoit Laudet ${ }^{2}$, \\ André Garnier ${ }^{2}$, Sylvine Guédon ${ }^{3}$ \\ ${ }^{1}$ Université Paris-Est, Laboratoire Navier-CERMES, Ecole des Ponts ParisTech, Marne la \\ Vallée, France \\ ${ }^{2}$ TOTAL, Management of Residual Gases Project, Pau, France \\ ${ }^{3}$ Université Paris-Est, IFSTTAR, Paris, France
}

\section{Abstract}

The experimental results of isotropic compression tests performed at $20^{\circ} \mathrm{C}$ and $90^{\circ} \mathrm{C}$ on a class $\mathrm{G}$ hardened cement paste hydrated at $90^{\circ} \mathrm{C}$ (Ghabezloo et al., 2008, Cem. Conc. Res. 38, 1424-1437) have been revisited considering time-dependent response. Within the frame of a viscoplastic model, the non-linear responses of the volumetric strains as observed in drained and undrained tests and of the pore pressure in undrained tests are analysed. The calibration of model parameters based on experimental data allows to study the effect of the test temperature on the viscous response of hardened cement paste showing that the creep is more pronounced for a higher test temperature. The effect of the hydration temperature on the time dependent behaviour is also studied by evaluating the model parameters for a cement paste hydrated at $60^{\circ} \mathrm{C}$. The time-dependent deformations are more pronounced for hydration at a higher temperature.

Please cite this paper as: Vu, M.H., Sulem, J., Ghabezloo, S., Laudet, J.B., Garnier, A., Guédon, S. (2012) Time-dependent behaviour of hardened cement paste under isotropic loading, Cement and Concrete Research, doi: 10.1016/j.cemconres.2012.03.002 


\section{Introduction}

For cementing an oil well, the cement slurry is pumped into the annular space between the casing and the rock around the well. This cement sheath plays a very important role during the life of the well from the drilling phase to the production phase and finally in the abandon phase. It provides zonal isolation in the well, i.e. it excludes fluids from one zone to another. It supports also the casing and protects it against corrosion. This cement sheath is submitted to various thermal and mechanical solicitations during the life of the well. In due course of these solicitations, the cement can be damaged and its mechanical and transport properties can be degraded, this degradation being detrimental to its main functions. The knowledge of thermoporo-mechanical behaviour of these cements in oil-well conditions, i.e. under high pressure and temperature, is therefore essential for prediction of the well performance. In the abandon phase, it is also crucial to assess the sealing performance of the well when the reservoir is used for storage and sequestration of greenhouse gas.

Recently Ghabezloo et al. [1][2][3][4] studied experimentally the thermo-poro-mechanical behaviour of a hardened oil-well cement paste. They performed classical poromechanical tests such as drained, undrained and unjacketed isotropic compression tests, as well as drained and undrained heating tests and permeability evaluation tests. As an answer to the question raised by Ulm et al. [5], the results presented by Ghabezloo et al. [1] show clearly that the behaviour of hardened cement paste can be described within the framework of the classical theory of porous media. The effects of water-to-cement ratio and chemical composition of the cement on the evaluated thermo-poro-elastic parameters have been studied by association of the experimental results with micromechanics modelling and homogenization method [6][7][8]. Revisiting the experimental data of Ghabezloo et al. [1], we observe a nonlinear response and hysteresis loops during unloading-reloading cycles of isotropic compression tests reflecting viscous behaviour of the material. Time dependent deformation was also observed and analysed while evaluating the permeability of the hardened cement paste in a transient test [4]. Nevertheless, the viscous behaviour of the material was not considered in the analysis of the results of isotropic compression tests presented in [1]. One purpose of the present paper is therefore to study the time dependent behaviour of the hardened cement paste under high stresses and temperature. Creep tests under isotropic stress presented in [2] show that the creep is more pronounced at higher stress and higher temperature. These observations highlight the importance of time dependent deformations for oil cement sheath at great depth. 
A degradation of the interface between the cement sheath and the rock can induce the formation of a micro-annular around the well. This micro-annular allows leakage of gas and fluid which can affect the performance and the safety of the well.

The present study is a continuation of previous experimental research on the poromechanical behaviour of hardened class $\mathrm{G}$ cement paste. Emphasis is given in this paper on the effect of test temperature on the time-dependent behaviour considering drained and undrained isotropic tests on hardened cement paste hydrated at $90^{\circ} \mathrm{C}$. A rheological model is proposed and calibrated on drained isotropic compression tests data. The validation of the model is performed by simulation of other tests: a drained compression test with different back pressure, a creep test and an undrained isotropic compression test. A discussion on the effect of the test temperature on the parameters of the model is presented. The mechanisms of timedependent behaviour of hardened cement paste are also discussed. Finally the model is applied to analyse experimental data from a drained isotropic compression test performed on a cement paste hydrated at a different temperature in order to study the effect of the hydration temperature on the creep of the material.

\section{Experimental observations}

In the experimental study of Ghabezloo et al. [1], a class $\mathrm{G}$ cement was used to prepare the cement paste with a water to cement ratio w/c $=0.44$. After 3 months of hydration at $90^{\circ} \mathrm{C}$, cylindrical specimens with $38 \mathrm{~mm}$ diameter and $76 \mathrm{~mm}$ length were fabricated. Drained and undrained isotropic compression tests as well as an unjacketed compression test were performed at $20^{\circ} \mathrm{C} \mathrm{[1]}$. Drained triaxial compression tests were also performed at $90^{\circ} \mathrm{C}$ [2]. For all tests, few loading-unloading cycles were performed at different stress levels (around $20 \mathrm{MPa}, 40 \mathrm{MPa}$ and $60 \mathrm{MPa}$ ). The loading rate was $0.025 \mathrm{MPa} / \mathrm{min}$ and $0.10 \mathrm{MPa} / \mathrm{min}$ for drained tests and undrained tests respectively.

The stress-strain response of drained tests is presented in Erreur! Source du renvoi introuvable. for samples hydrated at $90^{\circ} \mathrm{C}$ and tested at $20^{\circ} \mathrm{C}$ [1] and $90^{\circ} \mathrm{C}$ [2]. We can observe the non-linear response of the hardened cement paste under isotropic compression. The unloading-reloading cycles show a hysteresis which is more pronounced at higher Terzaghi effective stress level. Under higher stress, one can see that the volumetric strain continues to increase at the beginning of the unloading parts. This clearly reflects the viscous behaviour of the material under isotropic compression. The non-elastic strains at the end of unloading are quite small $(<0.3 \%)$ when the Terzaghi effective stress level at the beginning of 
the unloading is lower than about $43 \mathrm{MPa}$ and $25 \mathrm{MPa}$ for the tests $T_{\mathrm{t}} 20$ and $T_{t} 90$ respectively. The volumetric strain increases with a much higher rate and the non-elastic strains become much higher beyond these stress levels. This suggests that an additional mechanism, such as microcrack development or collapse of the Large Gel Pores (LGP), i.e. with a size between $3 \mathrm{~nm}$ and $12 \mathrm{~nm}$ [9], is activated when the stress is high enough and accelerates the development of volumetric strain (see section 5). This mechanism occurs at lower stress levels when test temperature is higher. The sample tested at $90^{\circ} \mathrm{C}$ exhibits a lower tangent elastic modulus. Moreover, the volumetric strain is larger and the viscous effects are more pronounced for this test temperature.

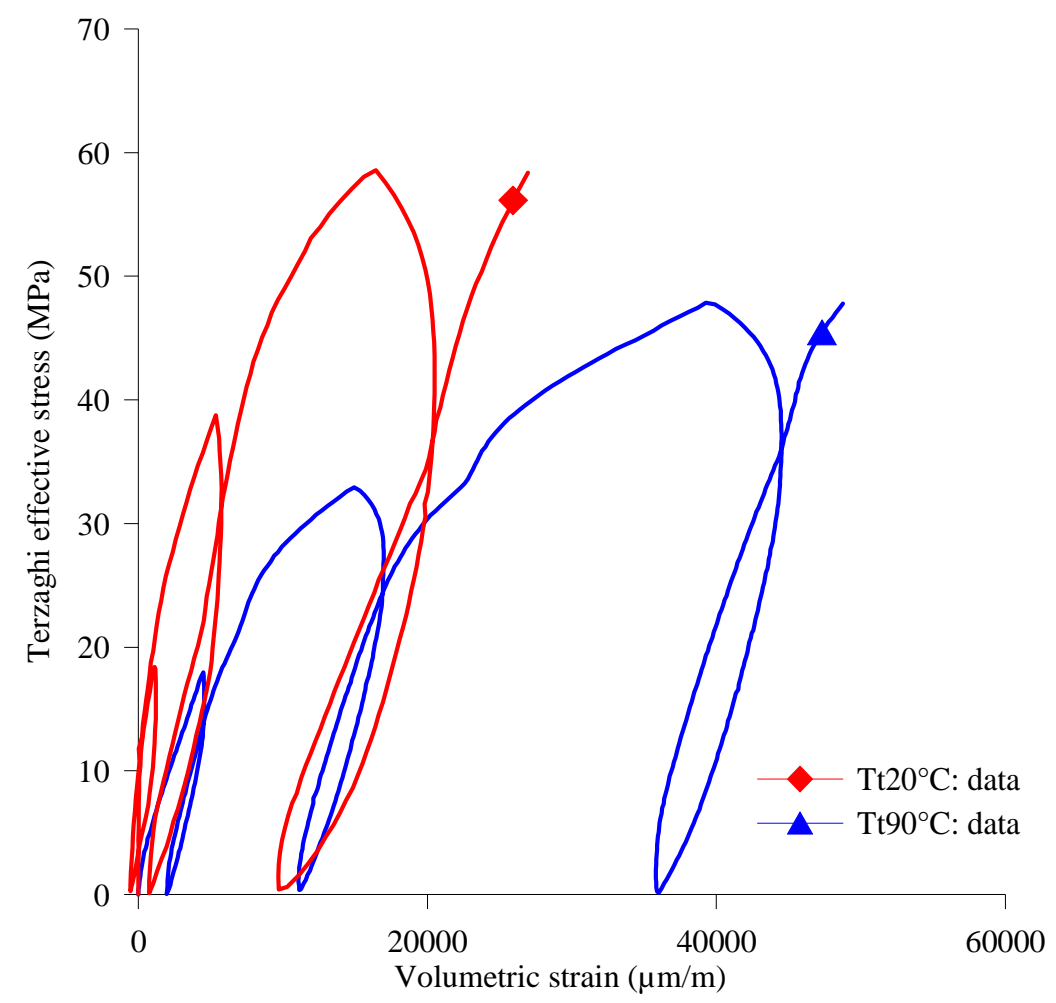

Figure 1 : Drained isotropic compression tests: Volumetric strain- Terzaghi effective stress $\left(T_{t}\right.$ is the test temperature) $[1][2]$

For the undrained test performed at $20^{\circ} \mathrm{C}$, the maximal pressure reached $58.0 \mathrm{MPa}$ and the pore pressure reached 26.5 MPa that corresponds to a Terzaghi effective stress of $31.5 \mathrm{MPa}$ (Figure 2). The non-elastic strains remain small which is consistent with a maximal Terzaghi effective stress lower than the stress threshold (43 MPa). The pore pressure-confinement pressure curve in Figure 2 shows that the reloading phases are quite linear whereas the unloading phases are highly non-linear. One observes that in the beginning of the unloading phases, the decrease of the pore pressure is delayed. At $12 \mathrm{MPa}$, the pore pressure becomes equal to the confinement pressure. In triaxial cells, in this situation the pore fluid infiltrates 
between the specimen and the jacket and in consequence the decrease of the pore pressure until the end of the unloading phase is pursued with a slope of 1:1. The slope of linear part of reloading phases, equal to 0.4, was chosen by Ghabezloo et al. [1] as Skempton coefficient. However, the delayed decrease of the pore pressure at the beginning of unloading phases was not explained in [1] in the framework of poro-elasticity theory.

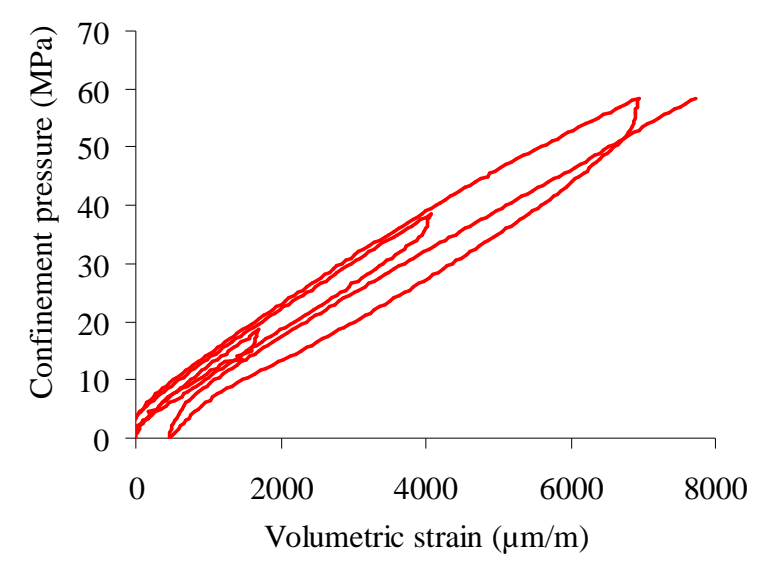

(a)

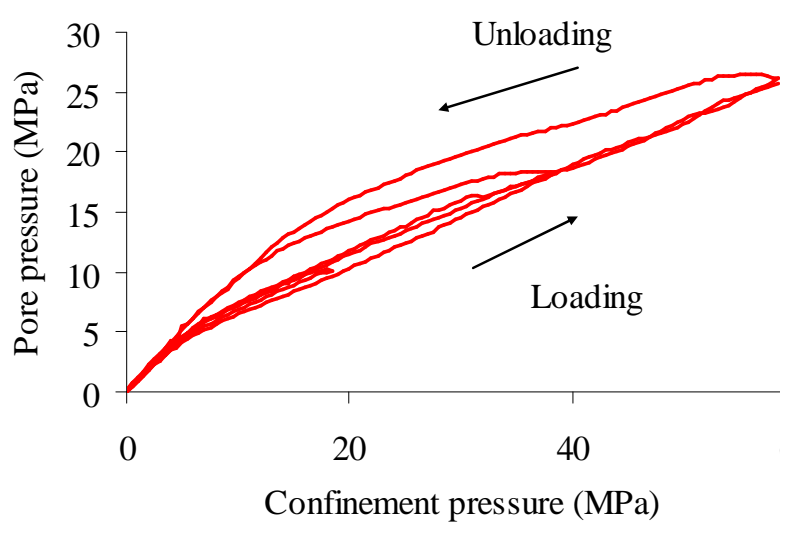

(b)

Figure 2 : Undrained isotropic compression test at $T_{\mathrm{t}}=20^{\circ} \mathrm{C}[1]$,

(a) volumetric strain response, (b) pore pressure response

\section{Viscoplastic modelling}

As mentioned above, the unloading-reloading cycles under drained isotropic compression exhibit a degree of hysteresis which increases with the stress level. This phenomenon reflects the viscous behaviour of the material. Moreover, the volumetric strain and viscous effects are enhanced at higher stress and depend upon the test temperature. One can consider that under low stress level, time dependent deformation has a viscoelastic nature (primary creep) and at higher stresses, an additional irreversible component is triggered and viscoplastic strains develop beyond a stress threshold (secondary creep). In the following we postulate a rheological model describing the viscoplastic behaviour of the hardened cement paste under drained isotropic compression. After calibration of the model parameters on the drained compression tests, the evolutions of volumetric strain and pore pressure during an undrained compression test are computed and compared with the experimental data. 


\subsection{Drained isotropic compression}

The response of the material is described by the rheological model depicted in Figure 3. The model contains two groups of elements: a viscoelastic Kelvin element which represents the viscoelastic part and a Maxwell element in parallel with a sliding friction element which represents the irreversible part of the deformation. In the Kelvin element, the linear spring (bulk modulus $K_{0}$ ) represents the time independent volumetric strain, and the Voigt element with a linear spring (bulk modulus $K_{1}$ ) and a dashpot (viscosity $\eta_{1}$ ) in parallel represents the primary creep deformation. The viscoplastic component includes a sliding frictional element which is activated only for stresses exceeding a given Terzaghi effective stress threshold $\sigma_{\mathrm{s}}$ [10] and results in time dependent volumetric deformation which develops at constant rate under constant load (bulk modulus $K_{2}$, and viscosity $\eta_{2}$ ). The six parameters of the rheological model are assumed to be constant for a given test temperature.

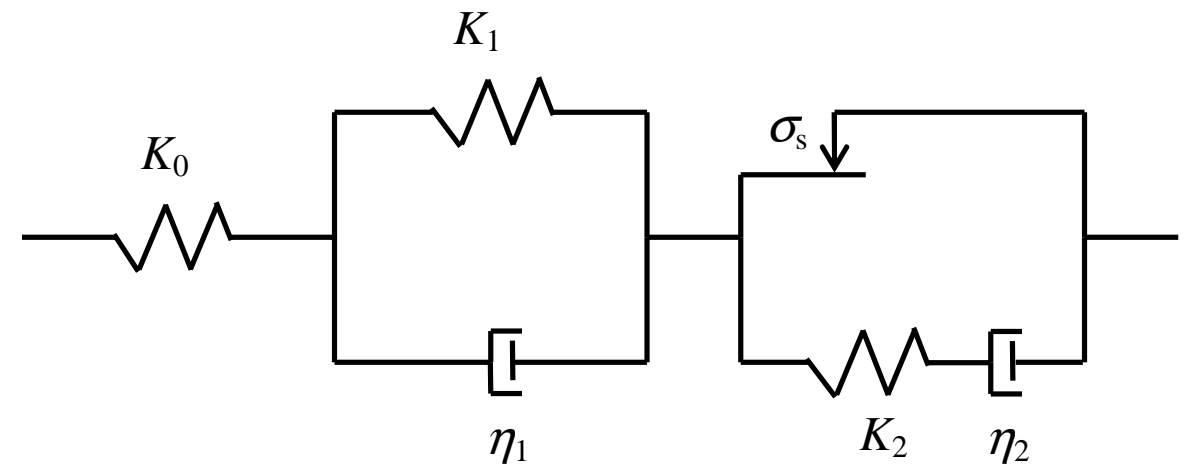

Figure 3 : Rheological model

The overall volumetric strain under a Terzaghi effective stress $\sigma_{d}$ is written as the sum of the viscoelastic part $\mathcal{E}_{\mathrm{ve}}$ and the viscoplastic part $\varepsilon_{\mathrm{vp}}$ :

$$
\varepsilon=\varepsilon_{\mathrm{ve}}+\varepsilon_{\mathrm{vp}}
$$

where $\varepsilon_{\mathrm{ve}}=\varepsilon_{0}+\varepsilon_{1}$. The strain rate for each element can be written as:

$$
\begin{gathered}
\dot{\varepsilon}_{0}=\frac{\dot{\sigma}_{d}}{K_{0}} \\
\dot{\varepsilon}_{1}=\frac{1}{\eta_{1}}\left(\sigma_{d}-K_{1} \varepsilon_{1}\right)
\end{gathered}
$$




$$
\dot{\varepsilon}_{\mathrm{vp}}=\left(\frac{\dot{\sigma}_{d}^{\mathrm{vp}}}{K_{2}}+\frac{\sigma_{d}^{\mathrm{vp}}}{\eta_{2}}\right) \mathrm{H}\left[\frac{\dot{\sigma}_{d}^{\mathrm{vp}}}{K_{2}}+\frac{\sigma_{d}^{\mathrm{vp}}}{\eta_{2}}\right] ; \quad \sigma_{d}^{\mathrm{vp}}=\left(\sigma_{d}-\sigma_{s}\right) \mathrm{H}\left[\sigma_{d}-\sigma_{s}\right]
$$

where $\mathrm{H}$ is the Heaviside function. It is worth to note that in the beginning of the unloading phase, the viscoplastic strain continues to increase until $\left(\dot{\sigma}_{d}^{\mathrm{vp}} / K_{2}+\sigma_{d}^{\mathrm{vp}} / \eta_{2}\right)$ becomes negative. Then the rate of viscoplastic strain is nil and the sliding friction element is blocked.

\section{Remark:}

Note that for $t \gg t_{f}$, where $t_{f}=\eta_{1} / K_{1}$ is the creep time of the viscoelastic component, and for an imposed stress $\sigma_{d}>\sigma_{s}$, the rheological model is reduced to a simple Maxwell element. This Maxwell element has a stiffness $K_{e q}$ and a viscosity $\eta_{e q}$ given by

$$
\frac{1}{K_{e q}}=\frac{1}{K_{0}}+\frac{1}{K_{1}}+\frac{\left(1-\sigma_{s} / \sigma_{d}\right)}{K_{2}} \quad ; \quad \eta_{e q}=\frac{\eta_{2}}{\left(1-\sigma_{s} / \sigma_{d}\right)}
$$

The equivalent stiffness decreases with increasing stress which can be interpreted as damage effect under elevated stress (Ghabezloo et al. [1]).

The viscoelastic strain can be found using Laplace transformation. For an arbitrary function $f$, the Laplace transform $\mathcal{L}$, denoted $\bar{f}$ is defined as:

$$
\mathcal{L}(f(t))=\bar{f}(s)=\int_{0}^{\infty} f(t) e^{-s t} d t
$$

In the Laplace transform domain, the viscoelastic strain is written as:

$$
\bar{\varepsilon}_{\mathrm{ve}}=\left(\frac{1}{K_{0}}+\frac{1}{K_{1}+\eta_{1} s}\right) \bar{\sigma}_{d}
$$

The viscoplastic part of the model exhibits a different response in loading and unloading due to the presence of the sliding frictional element. No general closed-form solution can be derived and a numerical solution is required. For this purpose a finite difference scheme is used. Figure 4 presents the loading path with the unloading-reloading cycles performed at constant rates $V_{i}$ during the isotropic drained compression tests. The corresponding evolution in time of the applied stress is expressed as:

$$
\sigma_{d}(t)=V_{0} t+\sum_{i=1}^{n}(-1)^{i}\left(V_{i-1}+V_{i}\right)\left(t-t_{i}\right) \mathrm{H}\left[t-t_{i}\right]
$$


where the parameters $t_{i}$ are the times at which the sign of the loading rate is changed. Equation (8) is written in the Laplace transform field as:

$$
\bar{\sigma}_{d}=\frac{1}{s^{2}}\left[V_{0}+\sum_{i=1}^{n}(-1)^{i}\left(V_{i-1}+V_{i}\right) e^{-t_{i} s}\right]
$$

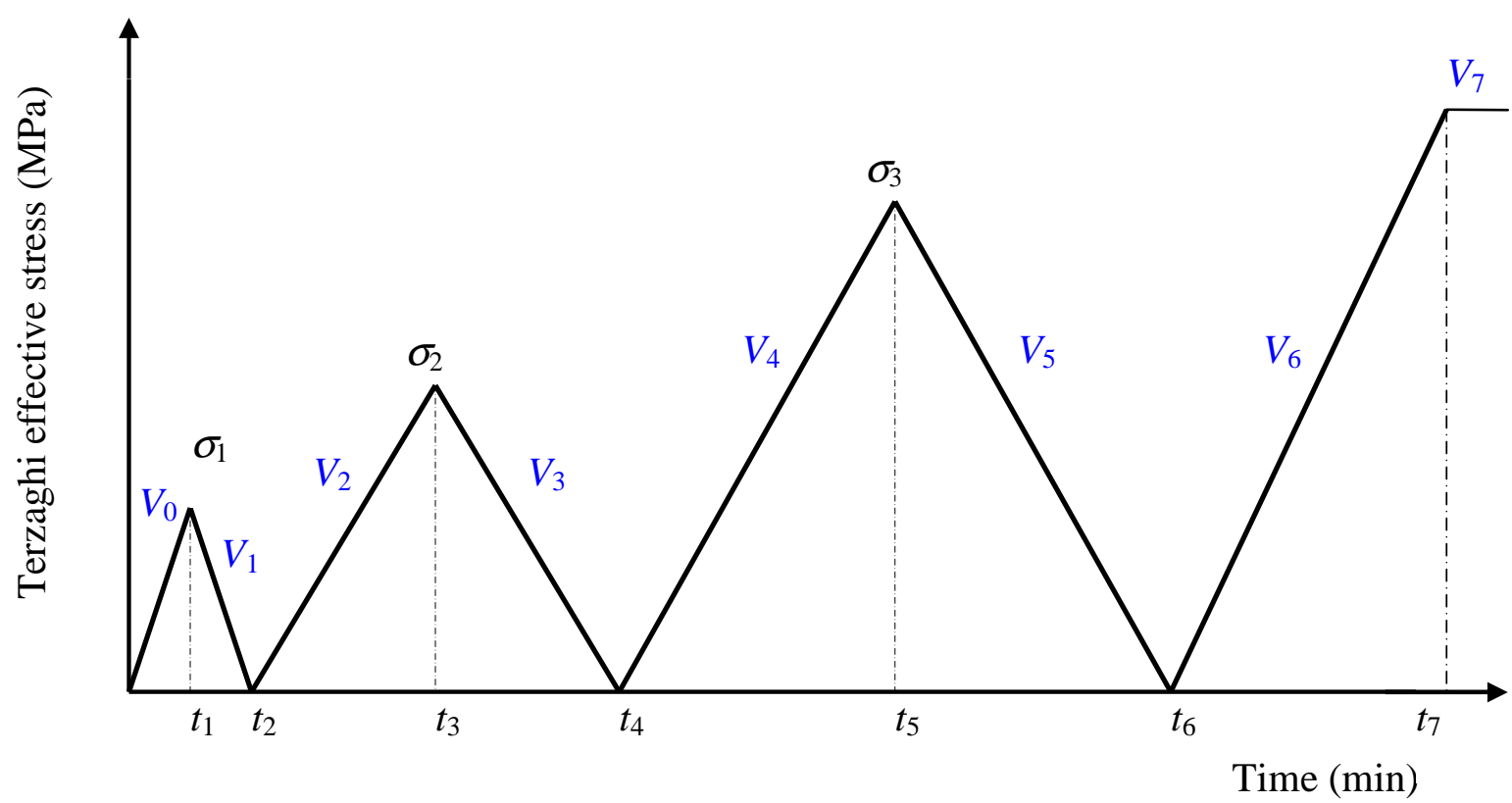

Figure 4 : Cycles loading-unloading

Replacing equations (8) and (9) in equation (7) and inverting the Laplace transform, the analytical solution of the viscoelastic part $\varepsilon_{\mathrm{ve}}$ of the volumetric strain for drained isotropic compression is obtained as:

$$
\begin{aligned}
\mathcal{E}_{\mathrm{ve}}(t)= & \frac{V_{0}}{a_{3}^{2}}\left[a_{3} a_{1}+\left(a_{2} a_{3}-a_{1} a_{4}\right)\left(1-e^{-\frac{a_{3}}{a_{4}} t}\right)\right] \\
& +\frac{1}{a_{3}^{2}} \sum_{i=1}^{n}(-1)^{i}\left(V_{i-1}+V_{i}\right) \mathrm{H}\left[t-t_{i}\right]\left[a_{3} a_{1}\left(t-t_{i}\right)+\left(a_{2} a_{3}-a_{1} a_{4}\right)\left(1-e^{-\frac{a_{3}}{a_{4}}\left(t-t_{i}\right)}\right)\right]
\end{aligned}
$$

where $a_{1}=K_{0}+K_{1}, a_{2}=\eta_{1}, a_{3}=K_{1} K_{0}$ and $a_{4}=K_{0} \eta_{1}$. 


\subsection{Undrained isotropic compression}

The correspondence principle between poro-elasticity and poro-viscoelasticity is used here to calculate the poro-viscoelastic parameters. For solid materials under isotropic loading, the relationship between the applied confinement pressure and volumetric strain can be expressed by the hereditary integral [11][12]:

$$
\sigma(t)=\int_{-\infty}^{+\infty} \hat{K}\left(t-t^{\prime}\right) \dot{\varepsilon} d t^{\prime}
$$

where $\hat{K}\left(t-t^{\prime}\right)$ is the relaxation modulus at instant $t^{\prime}$. By using the principle of superposition and in the same way one can write the equivalent expressions for a poro-viscoelastic material under isotropic loading as [13]:

$$
\begin{gathered}
\sigma_{c}(t)-\int_{-\infty}^{+\infty} \hat{\alpha}\left(t-t^{\prime}\right) \dot{p} d t^{\prime}=\int_{-\infty}^{+\infty} \hat{K}\left(t-t^{\prime}\right) \dot{\varepsilon} d t^{\prime} \\
p_{f}(t)=\int_{-\infty}^{+\infty} \hat{N}\left(t-t^{\prime}\right) \dot{\phi} d t^{\prime}-\left[\int_{-\infty}^{+\infty} \hat{K}_{s}\left(t-t^{\prime}\right) \dot{\varepsilon} d t^{\prime}+\phi_{0} \int_{-\infty}^{+\infty} \hat{N}\left(t-t^{\prime}\right) \dot{\varepsilon} d t^{\prime}\right]
\end{gathered}
$$

where $N$ is the Biot modulus; $\sigma_{c}(t)$ and $p_{f}(t)$ are confinement pressure and pore pressure respectively; $\hat{\alpha}\left(t-t^{\prime}\right)$ is a coefficient corresponding to the variation of confinement pressure over a unit of pore pressure change at time $t^{\prime}$ when the volumetric strain is maintained constant. By writing equations (12) and (13) in the Laplace transform domain and knowing that $\overline{\int_{-\infty}^{+\infty} f(t) \dot{g}(t) d t}=s \bar{f} \times \bar{g}$, one obtains:

$$
\begin{gathered}
\bar{\sigma}_{c}-\tilde{\alpha} \bar{p}_{f}=\tilde{K}_{d} \bar{\varepsilon} \\
\bar{p}_{f}=\tilde{N} \overline{\left(\phi-\phi_{0}\right)}-\left(\tilde{K}_{s} \bar{\varepsilon}+\phi_{0} \tilde{N} \bar{\varepsilon}\right)
\end{gathered}
$$

where

$$
\tilde{\alpha}=s \overline{\hat{\alpha}} \quad ; \quad \tilde{K}_{d}=s \overline{\hat{K}}_{d} \quad ; \quad \tilde{K}_{s}=s \overline{\hat{K}}_{s} \quad ; \tilde{N}=s \overline{\hat{N}}
$$

For isotropic undrained compression tests with a constant loading rate $V$, the confinement pressure is written in the Laplace transform domain as:

$$
\bar{\sigma}_{c}=\frac{1}{s^{2}}\left[V_{0}+\sum_{i=1}^{n}(-1)^{i}\left(V_{i-1}+V_{i}\right) e^{-t_{i} s}\right]
$$


The equations of poro-viscoelasticity written in the Laplace transform domain are formally similar to those of poro-elasticity. From equation (7), the expression of the drained bulk modulus in the Laplace transform domain is given as:

$$
\tilde{K}_{d}=\frac{1}{1 / K_{0}+1 /\left(K_{1}+\eta_{1} s\right)}
$$

By performing an unjacketed test at $20^{\circ} \mathrm{C}$, Ghabezloo et al. [1] found that the solid phase of hardened cement paste behaves elastically and that its compression modulus $K_{s}$ is constant and equal to $21.0 \mathrm{GPa}$, hence $\tilde{K}_{s}=K_{s}$. For undrained isotropic compression tests, the followed expressions can be written for the pore pressure and volumetric strain responses:

$$
\begin{gathered}
\bar{p}_{f}=\tilde{B} \bar{\sigma} \\
\varepsilon_{\mathrm{ve}}^{\mathrm{u}}=\frac{\bar{\sigma}}{\tilde{K}_{u}}
\end{gathered}
$$

One can evaluate the coefficients $\tilde{K}_{u}$ and $\tilde{B}$ using the following expressions [13]:

$$
\begin{gathered}
\tilde{K}_{u}=\frac{\tilde{K}_{d}}{1-\tilde{B}\left(1-\tilde{K}_{d} / K_{s}\right)} \\
\tilde{B}=\frac{1 / \tilde{K}_{d}-1 / K_{s}}{\left(1 / \tilde{K}_{d}-1 / K_{s}\right)+\phi\left(1 / K_{f}-1 / K_{s}\right)}
\end{gathered}
$$

where $\tilde{K}_{d}$ is expressed by equation (18). The coefficients $\tilde{K}_{u}$ and $\tilde{B}$ are functions of $K_{0}, K_{1}$, $\eta_{1}, K_{f}, K_{s}$ and $\phi$. Replacing equations (17), (21) and (22) in equations (19) and (20) and inverting the Laplace transform, the pore pressure $p_{f}$ and the volumetric strain $\varepsilon_{\mathrm{ve}}^{\mathrm{u}}$ are calculated. The solutions are written under the following form:

$$
\begin{aligned}
\omega(t)= & \frac{V_{0}}{a_{3}^{2}}\left[a_{3} a_{1}+\left(a_{2} a_{3}-a_{1} a_{4}\right)\left(1-e^{-\frac{a_{3}}{a_{4}} t}\right)\right] \\
& +\frac{1}{a_{3}^{2}} \sum_{i=1}^{n}(-1)^{i}\left(V_{i-1}+V_{i}\right) \mathrm{H}\left[t-t_{i}\right]\left[a_{3} a_{1}\left(t-t_{i}\right)+\left(a_{2} a_{3}-a_{1} a_{4}\right)\left(1-e^{-\frac{a_{3}}{a_{4}}\left(t-t_{i}\right)}\right)\right]
\end{aligned}
$$

where $\omega$ can be the volumetric strain $\varepsilon_{\mathrm{ve}}^{\mathrm{u}}$ or the pore pressure $p_{f}$. The parameters $a_{1}, a_{2}, a_{3}$ and $a_{4}$ for each case are given in Table 1. 
Table 1 : Parameters of equation (23) for drained and undrained tests

\begin{tabular}{|c|c|c|}
\hline$\omega(t)$ & $\varepsilon_{\mathrm{ve}}^{\mathrm{u}}$ & $p_{f}$ \\
\hline$a_{1}$ & $\frac{K_{0}+K_{1}}{\eta_{1}} a_{2}-K_{f} K_{0}^{2}$ & $K_{f}\left(K_{0} K_{s}-K_{0} K_{1}+K_{1} K_{s}\right)$ \\
\hline$a_{2}$ & $K_{f} K_{s} \eta_{1}\left(-1+\phi+\frac{K_{0}}{K_{s}}-\phi \frac{K_{s}}{K_{f}}\right)$ & $K_{f} \eta_{1}\left(K_{s}-K_{0}\right)$ \\
\hline$a_{3}$ & $\frac{K_{1}}{\eta_{1}} a_{4}-K_{0} K_{f} K_{s}^{2}$ & $a_{1}+\phi K_{0} K_{1}\left(K_{s}-K_{f}\right)$ \\
\hline$a_{4}$ & $K_{f} K_{0} K_{s} \eta_{1}\left(1+\phi-\frac{K_{s}}{K_{0}}-\phi \frac{K_{s}}{K_{f}}\right)$ & $a_{2}+\phi K_{0} \eta_{1}\left(K_{s}-K_{f}\right)$ \\
\hline
\end{tabular}

\section{Model calibration}

The parameters $K_{0}, K_{1}, \eta_{1}, K_{2}$ and $\eta_{2}$ of the viscoplastic model are calibrated on the drained isotropic compression tests for both test temperatures. Afterwards, theses values are validated for others tests performed at the same temperature. The values of $K_{0}, K_{1}, \eta_{1}$ and $K_{s}$ corresponding to $20^{\circ} \mathrm{C}$ are used to analyse the viscoelastic response under undrained isotropic loading for the test performed at ambient temperature.

\subsection{Drained isotropic compression tests}

Calibration of the model parameters is done as follows. The stress threshold $\sigma_{\mathrm{s}}$ is first estimated for different temperature conditions as the stress level above which the strain rate evaluated from the tests data changes significantly. The parameters of the viscoelastic part ( $\left.K_{0}, K_{1}, \eta_{1}\right)$ are evaluated for the part of the stress-strain curves corresponding to $\sigma \leq \sigma_{\mathrm{s}}$ and the two parameters of the viscoplastic part $\left(K_{2}, \eta_{2}\right)$ are calibrated in a second step for $\sigma>\sigma_{\mathrm{s}}$. The model parameters are evaluated using the least-square method by minimizing the error between the experimental results and the model predictions using a numerical solver. The computed parameters are listed in Table 2. The characteristic creep time and relaxation time 
for the viscoelastic element (i.e. under low stress) defined respectively as $\tau_{1}=\eta_{1} / K_{1}$ and $\tau_{2}=\eta_{1} /\left(K_{0}+K_{1}\right)$ are also reported in Table 2. With these parameters the computed curves are presented in Figure 5 along with the experimental results. One can see a good compatibility between the experimental and computed results. We also note that at $20^{\circ} \mathrm{C}$ the viscosity $\eta_{1}$ of the viscoelastic element is found equal to $46 \times 10^{5} \mathrm{MPa} . \mathrm{mn}$. This value is comparable with the one evaluated by Ghabezloo et al. [4], (from $26 \times 10^{5}$ to $39 \times 10^{5} \mathrm{MPa} . \mathrm{mn}$ ) from back analysis of transient permeability tests.

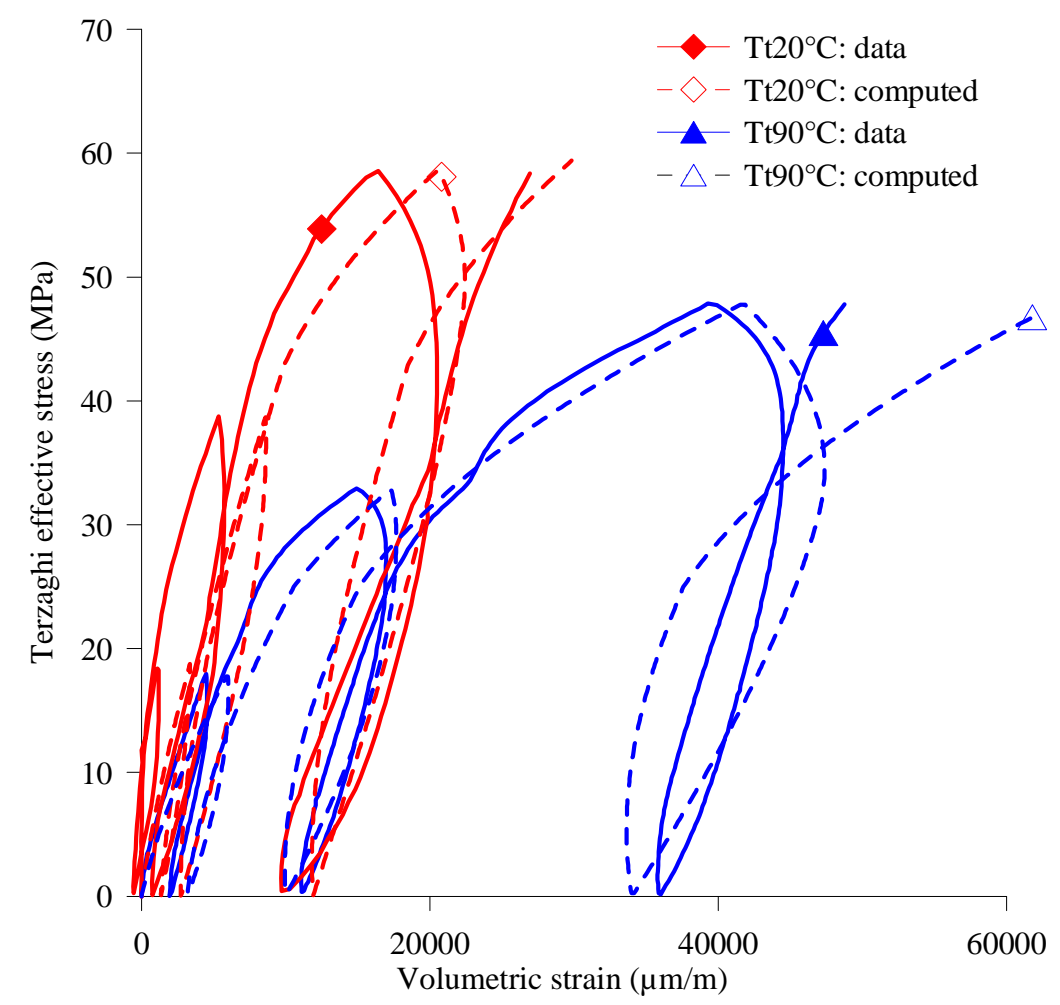

Figure 5 : Computed and experimental stress-strain curves under isotropic compression

Table 2 : Calibration of model parameters for a cement paste hydrated at $90^{\circ} \mathrm{C}\left(T_{\mathrm{h}} 90\right)$ and tested at $20^{\circ} \mathrm{C}$ and $90^{\circ} \mathrm{C}\left(T_{\mathrm{t}} 20, T_{\mathrm{h}} 90\right)$

\begin{tabular}{|c|c|c|c|c|c|c|c|c|c|}
\hline $\begin{array}{c}\boldsymbol{T}_{\mathbf{h}} \\
\left({ }^{(} \mathbf{C}\right)\end{array}$ & $\begin{array}{c}\boldsymbol{T}_{\mathbf{t}} \\
\left({ }^{\circ} \mathbf{C}\right)\end{array}$ & $\begin{array}{c}\boldsymbol{\sigma}_{\mathbf{s}} \\
(\mathbf{M P a})\end{array}$ & $\begin{array}{c}\boldsymbol{K}_{\mathbf{0}} \\
(\mathbf{M P a})\end{array}$ & $\begin{array}{c}\boldsymbol{K}_{\mathbf{1}} \\
(\mathbf{M P a})\end{array}$ & $\begin{array}{c}\boldsymbol{K}_{\mathbf{2}} \\
(\mathbf{M P a})\end{array}$ & $\begin{array}{c}\boldsymbol{\eta}_{\mathbf{1}} \\
(\mathbf{M P a} . \mathbf{m n})\end{array}$ & $\begin{array}{c}\boldsymbol{\eta}_{2} \\
(\mathbf{M P a} . \mathbf{m n})\end{array}$ & $\boldsymbol{\tau}_{1}(\mathbf{m n})$ & $\boldsymbol{\tau}_{2}(\mathbf{m n})$ \\
\hline \multirow{2}{*}{90} & 20 & 43 & 8000 & 5500 & 7000 & $46.0 \times 10^{5}$ & $12.0 \times 10^{5}$ & 836 & 341 \\
\cline { 2 - 10 } & 90 & 25 & 5000 & 3000 & 4300 & $22.0 \times 10^{5}$ & $8.5 \times 10^{5}$ & 733 & 275 \\
\hline
\end{tabular}

Using the calibrated model parameters, an isotropic compression test which is not used for model calibration is simulated. This test corresponds to a sample hydrated at $90^{\circ} \mathrm{C}$ and tested at $20^{\circ} \mathrm{C}$, referred as test D4 in Figure 4 of [1]. The comparison of the simulated stress-strain curve and the experimental result in Figure 6 shows a good compatibility. Moreover this test contains a creep phase at $36 \mathrm{MPa}$. The model correctly reproduces the creep phase as shown 
in Figure 7. A good accordance of measured and computed irreversible strains at the end of unloading phases of three tests presented above is also shown in Figure 8.

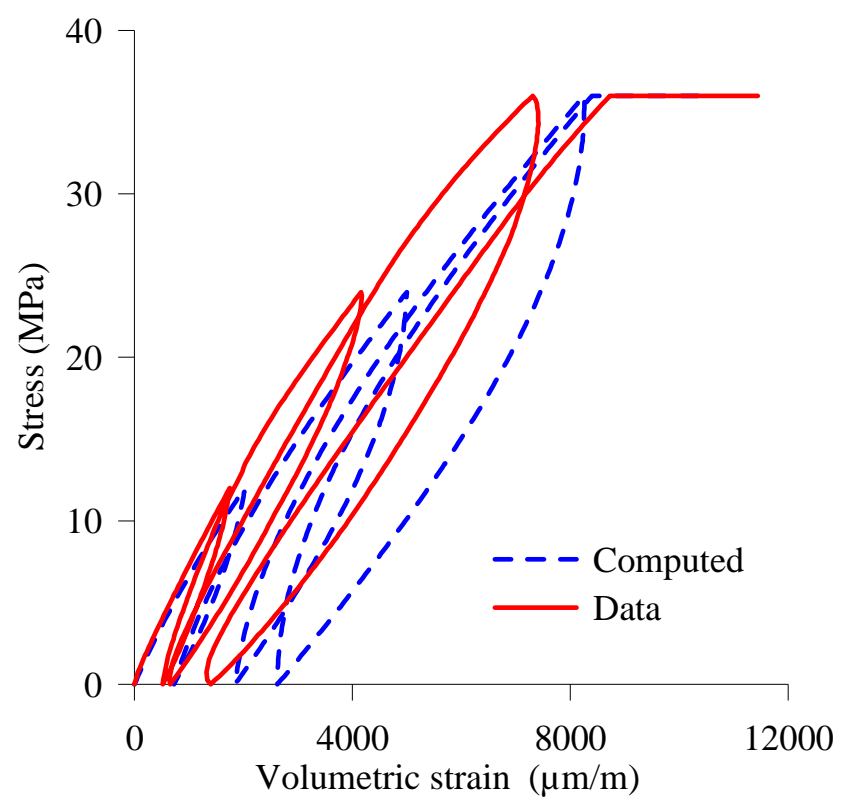

Figure 6 : Test D-4: Isotropic compression test at $20^{\circ} \mathrm{C}$ on a sample hydrated at $90^{\circ} \mathrm{C}$

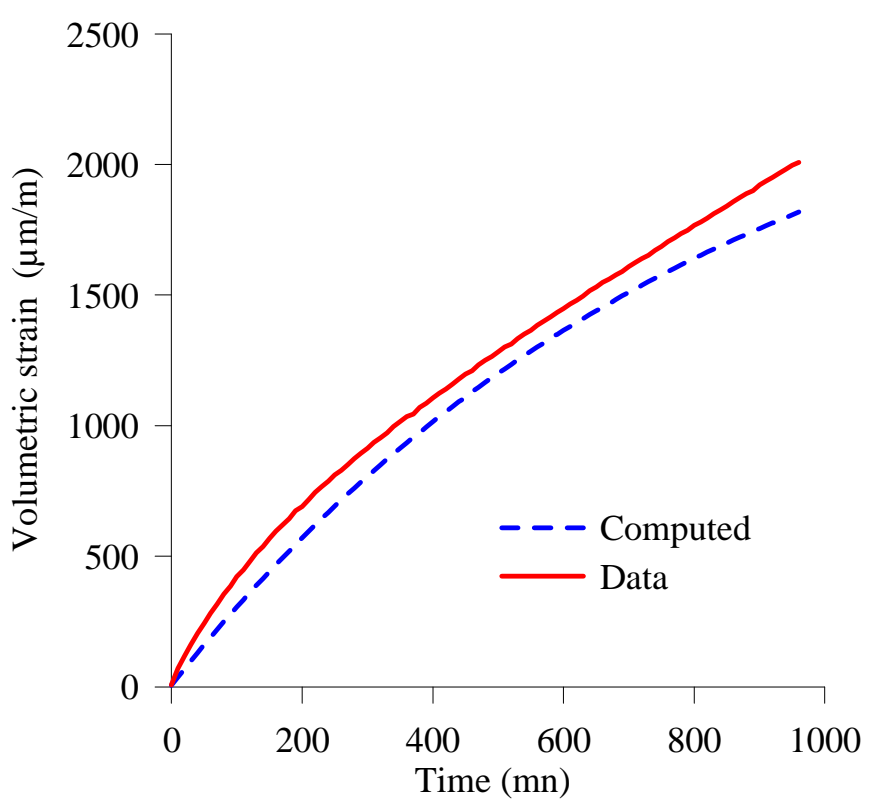

Figure 7 : Creep phase of Test D-4 (under $36 \mathrm{MPa}$ ) 


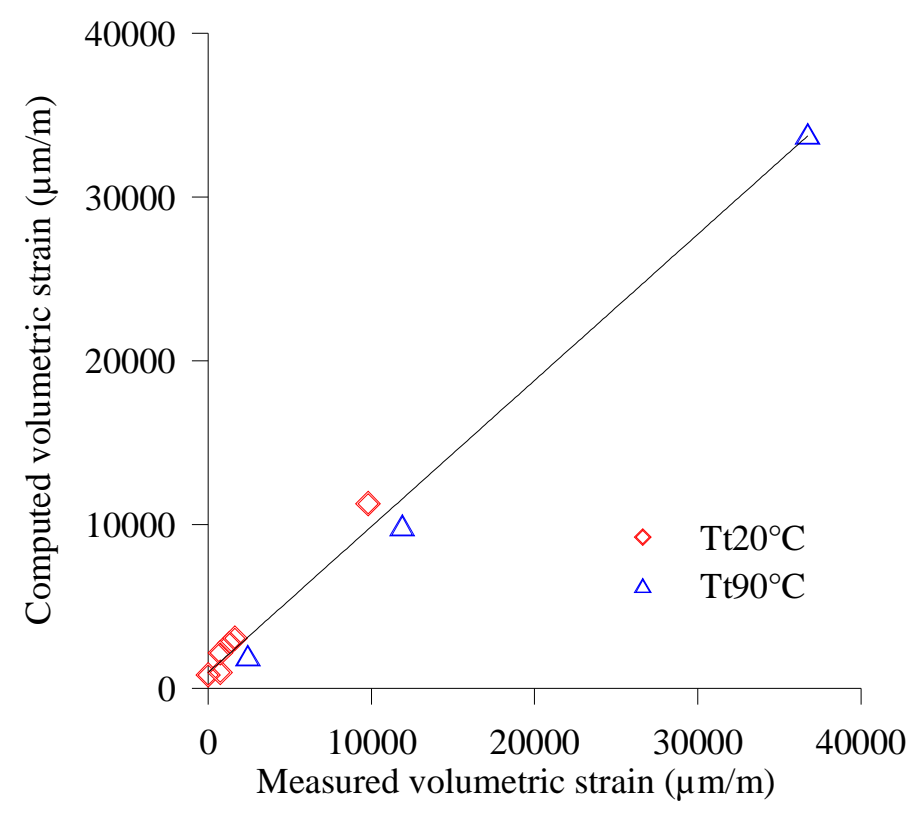

Figure 8 : Comparison of plastic strains in experimental results and model predictions

\subsection{Undrained isotropic compression test}

The parameters $K_{0}, K_{1}$ and $\eta_{1}$ calibrated on drained tests for the test temperature of $20^{\circ} \mathrm{C}$ are used to validate the model by simulation of the undrained test presented above. The unjacketed modulus $K_{\mathrm{s}}$ is equal to $21.0 \mathrm{GPa}$ [1]. In the experimental study of Ghabezloo et al. [1], the total porosity was found equal to 0.35 . However, more recent experimental results on a greater number of samples prepared in the same conditions give a value of 0.39 for a hardened class $\mathrm{G}$ cement paste hydrated at $90^{\circ} \mathrm{C}$ and this value is used here. At $20^{\circ} \mathrm{C}$, the bulk modulus of water $K_{f}$ is $2.2 \mathrm{GPa}$. The parameters are summarized in Table 3 and the simulation results are presented in Figure 9 which shows a very good agreement between the model predictions and the measurements of volumetric strain and pore pressure as function of confinement pressure. Note that the part of the simulated pore pressure-confinement pressure curve in which the pore pressure exceeds the confinement pressure is disregarded in this analysis, because as mentioned in section 2, this situation cannot occur in a triaxial cell. One can see in Figure 9 that the non-linear response of the pore pressure during the unloading phase is indeed well described by the model.

Table 3 : Model parameters for simulation of the undrained isotropic compression test at $20^{\circ} \mathrm{C}$

\begin{tabular}{|c|c|c|c|c|c|c|c|}
\hline $\begin{array}{c}\boldsymbol{T}_{\mathbf{h}} \\
\left({ }^{\circ} \mathbf{C}\right)\end{array}$ & $\begin{array}{c}\boldsymbol{T}_{\mathbf{t}} \\
\left({ }^{\circ} \mathbf{C}\right)\end{array}$ & $\begin{array}{c}\boldsymbol{K}_{0} \\
(\mathbf{M P a})\end{array}$ & $\begin{array}{c}\boldsymbol{K}_{1} \\
(\mathbf{M P a})\end{array}$ & $\begin{array}{c}\eta_{\mathbf{1}} \\
(\mathbf{M P a} . \mathbf{m n})\end{array}$ & $\begin{array}{c}\boldsymbol{K}_{f} \\
(\mathbf{M P a})\end{array}$ & $\begin{array}{c}\boldsymbol{K}_{s} \\
(\mathbf{M P a})\end{array}$ & $\boldsymbol{\phi}$ \\
\hline 90 & 20 & 8000 & 5500 & $46 \times 10^{5}$ & 2200 & 21000 & 0.39 \\
\hline
\end{tabular}




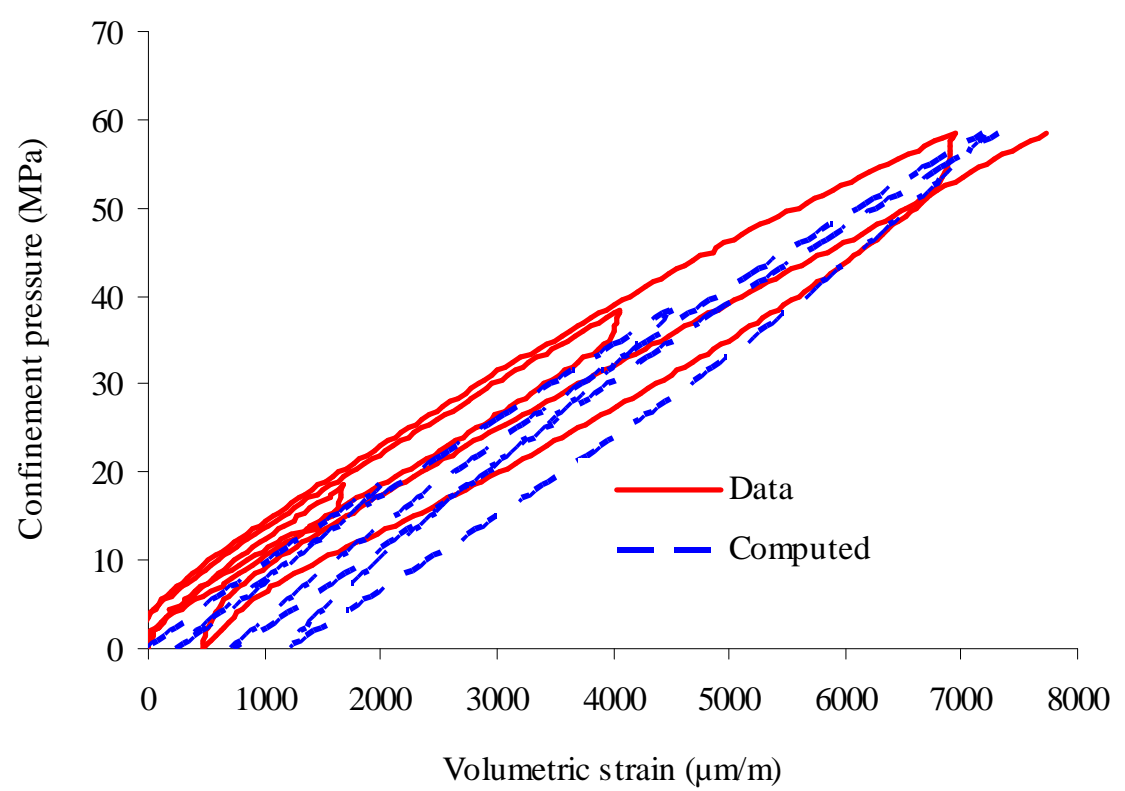

(a)

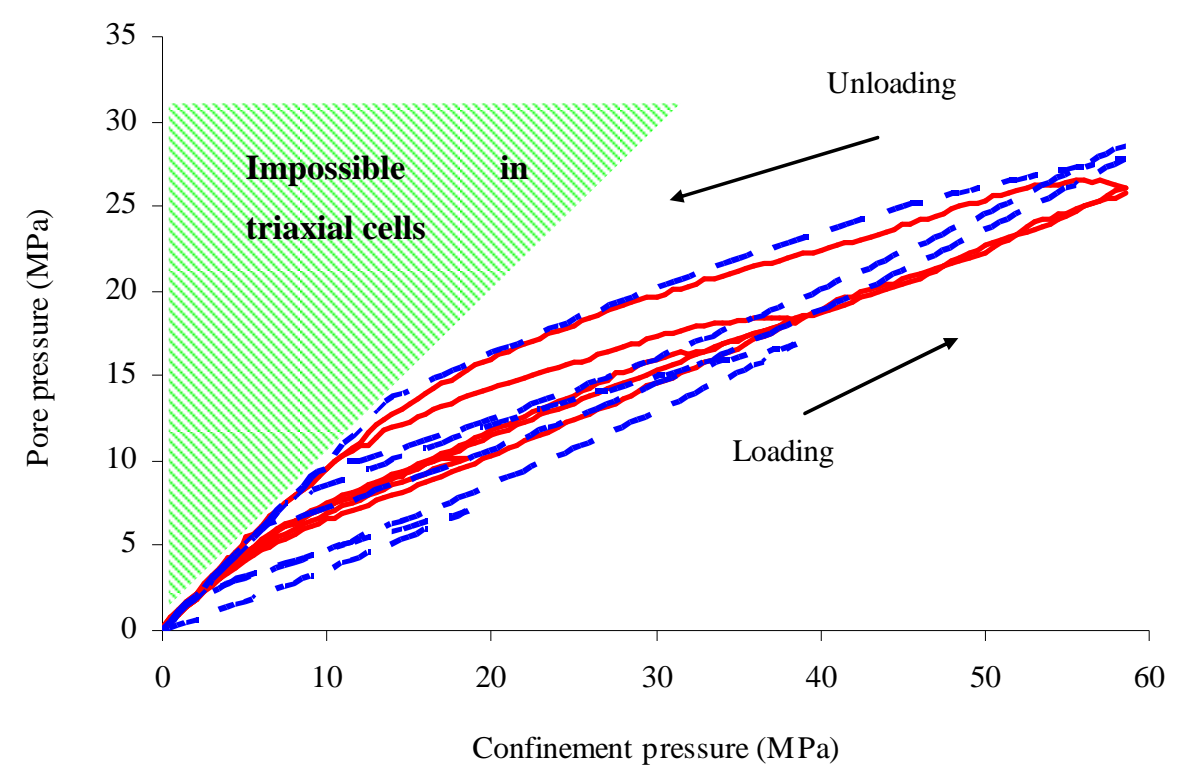

(b)

Figure 9 : Comparison of experimental results and model prediction for undrained isotropic compression test, (a) volumetric strain response, (b) pore pressure response

\section{Discussion}

As seen above, the proposed viscoplastic model allows to describe the time-dependent behaviour of hardened cement paste hydrated at $90^{\circ} \mathrm{C}$ under isotropic loading. It is interesting to try to relate this macroscopic model to the micromechanisms of creep of hardened cement paste. We explore also the effect of the test temperature on the parameters of the model. 


\subsection{Micromechanisms of creep}

Cement paste exhibits a complex microstructure including different phases such as hydration products, non-hydrated clinker, capillary pores and water. The main hydration products are Calcium Silicate Hydrate (C-S-H), Portlandite $(\mathrm{CH})$, Calcium Sulfoaluminate (Ettringite and Monosulfoaluminate). A set of experimental results of Velez et al. [14] and Nemecek [15] showed that unhydrated clinkers are not responsible for the time dependent behaviour of cement paste. The major hydration product, $\mathrm{C}-\mathrm{S}-\mathrm{H}$ is a porous phase with an amorphous and colloidal structure. Because of its large volume and its special microstructure, the properties of $\mathrm{C}-\mathrm{S}-\mathrm{H}$ have a dominant role for macroscopic properties, in particular the time-dependent behaviour of the cement paste. According to Jennings and Tennis [16], C-S-H exists in two types called high density (HD) C-S-H and low density (LD) C-S-H. Jennings et al. [17] and Jennings [18] postulated that the LD C-S-H and the HD C-S-H have the same fundamental unit, the so-called "globule". The difference between these two types of $\mathrm{C}-\mathrm{S}-\mathrm{H}$ is the arrangement of globules resulting in different gel porosity which is about $24 \%$ for HD C-S-H against $37 \%$ for LD C-S-H. Jennings [9] proposed a conceptual model for the microstructure of C-S-H composed of a fundamental unit being the C-S-H globule formed by dry solid sheet of C-S-H, intra-globule porosity filled with interlayer water and a monolayer of adsorbed water on the surface of the globule. The smallest pore in this microstructure is the IntraGlobular Pore (IGP) with the size smaller than $1 \mathrm{~nm}$ where water can escape and re-enter. The structure of C-S-H in Jennings' model contains Small Gel Pores (SGP) of a size between 1nm and $3 \mathrm{~nm}$ in the space between adjacent globules and Large Gel Pores (LGP) with a size between $3 \mathrm{~nm}$ and $12 \mathrm{~nm}$ between groups of several globules. Jennings et al. [19] showed that the properties of LD C-S-H and HD C-S-H are not modified by hydration temperature and this is compatible with the hypothesis of Ulm et al. [5] who supposed that the properties of LD C-S-H and HD C-S-H are their intrinsic characteristics.

Creep of cement paste is commonly attributed to two types of mechanisms: hydrodynamic phenomena and mechanical processes. Hydrodynamic origin of creep is linked to the movement of water in the small pores of C-S-H to reach pressure equilibrium [20] [21] [22][23][24][25]. This hydrodynamic relaxation is responsible for creep only at early time [20] [21] Erreur ! Source du renvoi introuvable. and is postulated to be reversible as, according to Jennings [9], the water can escape and re-enter even in the smallest pores (IGP). This argument is coherent with the fact that the total porosity, i.e. porosity measured by ovendrying at $105^{\circ} \mathrm{C}$ which includes a part of the interlayer water [25], is used in the poro- 
viscoelastic formulation simulating the undrained isotropic compression test at $20^{\circ} \mathrm{C}$ presented above. This is consistent with the fact that the hydrodynamic phenomenon occurs not only within large pores but also within small pores of HD C-S-H.

From the viscoelastic parameters presented in Table 2, it is clear that a relaxation time $\tau_{2}$ of the order of $300 \mathrm{~min}$ is much higher than the characteristic diffusion time of water at the scale of the small pores of C-S-H [20]. Other mechanisms such as sliding of C-S-H sheets are thus necessarily involved [27][28]. One also observes that the stiffness and viscosity parameters are lower at $90^{\circ} \mathrm{C}$ than at $20^{\circ} \mathrm{C}$. Thus the test temperature influences the primary creep. This result is in good agreement with the fact that creep is a thermally activated process [29]. At a higher test temperature, the sliding of $\mathrm{C}-\mathrm{S}-\mathrm{H}$ sheets is favourable due to a decrease of the viscosity of fluid with temperature. As a result, the time relaxation $\tau_{2}$ decreases with test temperature. A reduction of $19 \%$ of $\tau_{2}$ is found when the temperature increases from $20^{\circ} \mathrm{C}$ to $90^{\circ} \mathrm{C}$.

In general, the viscoplastic behaviour of cement paste is attributed to mechanical processes such as: collapse of large gel pores (LGP) [9] and time dependent microcrack development [23][28]. They occur when the stress is high enough leading to the development of irreversible strains. Such mechanisms can be described by the presence of a stress threshold in the viscoplastic part of the presented model. As this stress threshold is blocked when the rate of viscoplastic strain becomes nil, a part of strain is irreversible. From Table 2, it is observed that the stress threshold decreases with test temperature. This could be related to a weakening of the bonding forces between the globules at higher temperature which could trigger LGP collapse. The stiffness $K_{2}$ and viscosity $\eta_{2}$ also are lower at higher test temperature demonstrating an increase of the secondary creep with the test temperature.

\subsection{Effect of hydration temperature}

In an oil well, the temperature during hydration is the crucial factor that affects the microstructure and behaviour of the cement paste. It is thus important to investigate the effect of the hydration temperature on the time-dependent behaviour of the material. To do so, a drained isotropic compression test at $60^{\circ} \mathrm{C}$ has been performed on a sample hydrated at $60^{\circ} \mathrm{C}$. The loading path of the test includes three cycles with two different loading rates: 0.025 $\mathrm{MPa} / \mathrm{min}$ for the first two cycles and $0.010 \mathrm{MPa} / \mathrm{min}$ for the third one. The model presented above is calibrated on the experimental data and the parameters are presented in 
Table 4. Figure 10 shows a very good accordance between the simulation results and the experimental data. The stress threshold is found equal to $35 \mathrm{MPa}$. This value is between the ones obtained for the tests performed on samples hydrated at $90^{\circ} \mathrm{C}, 25 \mathrm{MPa}$ and $43 \mathrm{MPa}$ for test temperature of $20^{\circ} \mathrm{C}$ and $90^{\circ} \mathrm{C}$ respectively. It is observed that all the obtained stiffness and viscosity parameters are significantly larger, revealing the important role of the hydration temperature on time-dependent behaviour of cement paste. In particular, one can correlate the lower creep rate of cement paste hydrated at $60^{\circ} \mathrm{C}$ and the higher uniaxial strength (see Appendix). This trend is also in agreement with the measures of mercury porosity. A value of 0.23 has been found for a cement paste hydrated at $60^{\circ} \mathrm{C}$ against a value of 0.27 for the one hydrated at $90^{\circ} \mathrm{C}$.

Concerning the effect of hydration temperature on microstructure and elastic properties of hardened cement paste, Escalante-Garcia [30] noted that during hydration, a higher temperature increases the pore size of cement paste and the density of C-S-H but does not modify the total porosity. This is compatible with results of Jennings et al. [19] who showed that the hydration temperature increases the macroporosity. Moreover, it increases the volumetric fraction of HD C-S-H, and decreases the one of LD C-S-H without modifying their intrinsic properties. Consequently, concerning the mechanical properties of hardened cement paste, there exists a competition between the densification of C-S-H and the increase of macroporosity. The lower long term mechanical properties of cement paste hydrated at higher temperature observed in [31] [32] have shown the dominant role of macroporosity. This is also consistent with lower Young's modulus and uniaxial strength of cement paste hydrated at $90^{\circ} \mathrm{C}$ as presented in Appendix.

Concerning time-dependent behaviour of C-S-H, Jennings [9] suggested that LD C-S-H exhibits more creep than HD C-S-H due to the difference of porosity level. This statement is in good accordance with experimental results of Vandamme and Ulm [33] who found that creep is more important in LD C-S-H because of strong rearrangement of this component under loading. However, lower stiffnesses and viscosities obtained in our model for hardened cement paste hydrated at higher temperature highlight also the important role of macroporosity for time-dependent behaviour of the material. It is also reasonable to assume that a more heterogeneous microstructure of cement paste hydrated at higher temperature leads to higher micro-stresses. Therefore at higher hydration temperature, the sliding of C-S$\mathrm{H}$, the collapse of LGP and the propagation of microcracks could be favoured which could explain the lower values of the stiffnesses and viscosities obtained. 
Table 4 : Calibrated model parameters for a cement paste hydrated and tested at $60^{\circ} \mathrm{C}\left(T_{\mathrm{h}} 60-T_{\mathrm{t}} 60\right)$

\begin{tabular}{|c|c|c|c|c|c|c|c|c|c|}
\hline $\begin{array}{c}\boldsymbol{T}_{\mathbf{h}} \\
\left({ }^{\circ} \mathbf{C}\right)\end{array}$ & $\begin{array}{c}\boldsymbol{T}_{\mathbf{t}} \\
\left({ }^{\circ} \mathbf{C}\right)\end{array}$ & $\begin{array}{c}\boldsymbol{\sigma}_{\mathbf{s}} \\
(\mathbf{M P a})\end{array}$ & $\begin{array}{c}\boldsymbol{K}_{\mathbf{0}} \\
(\mathbf{M P a})\end{array}$ & $\begin{array}{c}\boldsymbol{K}_{\mathbf{1}} \\
(\mathbf{M P a})\end{array}$ & $\begin{array}{c}\boldsymbol{K}_{\mathbf{2}} \\
(\mathbf{M P a})\end{array}$ & $\begin{array}{c}\eta_{\mathbf{1}} \\
(\mathbf{M P a} . \mathbf{m n})\end{array}$ & $\begin{array}{c}\eta_{\mathbf{2}} \\
(\mathbf{M P a} . \mathbf{m n})\end{array}$ & $\boldsymbol{\tau}_{1}(\mathbf{m n})$ & $\boldsymbol{\tau}_{2}(\mathbf{m n})$ \\
\hline 60 & 60 & 35 & 8300 & 7200 & 13000 & $75.0 \times 10^{5}$ & $30.0 \times 10^{5}$ & 1041 & 483 \\
\hline
\end{tabular}

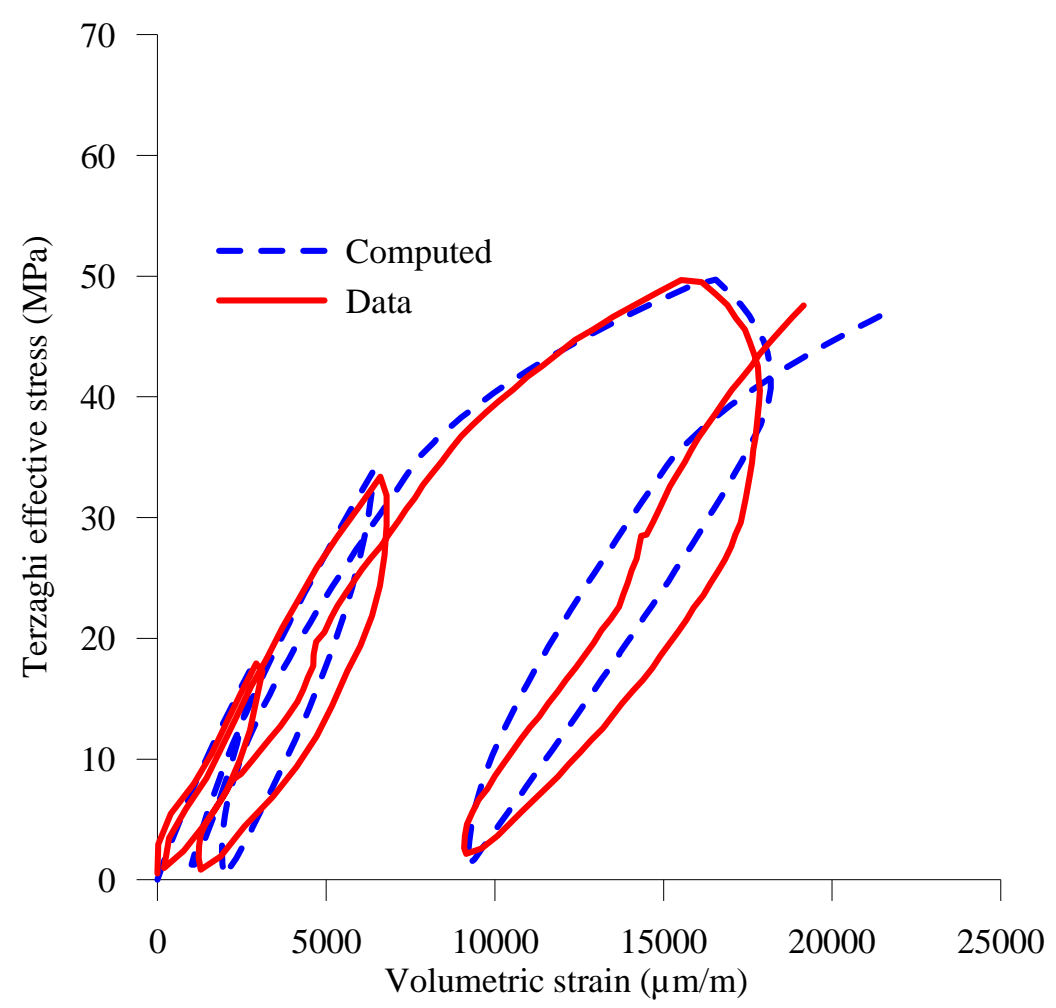

Figure 10 : Computed and experimental stress-strain curves under drained isotropic compression performed at $60^{\circ} \mathrm{C}$ on cement paste hydrated at $60^{\circ} \mathrm{C}$

\section{Conclusions}

Revisiting the isotropic compression tests on a hardened class $\mathrm{G}$ cement paste hydrated at $90^{\circ} \mathrm{C}$ in [1][2], we analyse in this paper the time dependent response. A viscoplastic model is proposed and calibrated on the experimental data. The model describes the non-linear response of the volumetric strain for both drained and undrained compression tests as well as the delayed response of the pore pressure in undrained tests. The parameters of the model reflect the effect of the test temperature on the viscoplastic properties of the hardened cement paste. It is shown that the creep of the material is more pronounced at higher test temperature. The effect of the hydration temperature on the creep of cement paste has also been discussed on the basis of the calibration of the model parameters on a drained isotropic compression test performed at $60^{\circ} \mathrm{C}$ on a sample hydrated at $60^{\circ} \mathrm{C}$. The obtained parameters allow to state that the creep is more pronounced at higher hydration temperature. 


\section{Appendix: Effect of the hydration temperature on the response of uniaxial compression tests}

Uniaxial compression tests have been performed at room temperature on samples hydrated at $60^{\circ} \mathrm{C}$ and on samples hydrated at $90^{\circ} \mathrm{C}$. A jacket is placed around the sample to avoid the evaporation of water during installation under the loading frame. The loading rate is relatively high $(7.5 \mathrm{MPa} / \mathrm{mn})$ so that the tests are performed in quasi-undrained condition. The results show that the strength and the Young's modulus of the cement hydrated at $60^{\circ} \mathrm{C}$ are both higher than those of the cement hydrated at $90^{\circ} \mathrm{C}$. To account for the natural variability of the mechanical properties of cement samples, the uniaxial strength and the Young's modulus are plotted versus the P-wave velocity of the intact sample in Figure 11 and Figure 12 respectively. From these graphs, one can observe that the strength of hardened cement paste hydrated at $60^{\circ} \mathrm{C}$ is around $55 \mathrm{MPa}$ while the values for a hydration temperature of $90^{\circ} \mathrm{C}$ are between $43 \mathrm{MPa}$ and $50 \mathrm{MPa}$. The Young's moduli are around 14.0GPa and 11.5GPa for a hydration temperature of $60^{\circ} \mathrm{C}$ and $90^{\circ} \mathrm{C}$ respectively. The stronger mechanical properties of cement paste hydrated at $60^{\circ} \mathrm{C}$ can be attributed to its smaller mercury porosity.

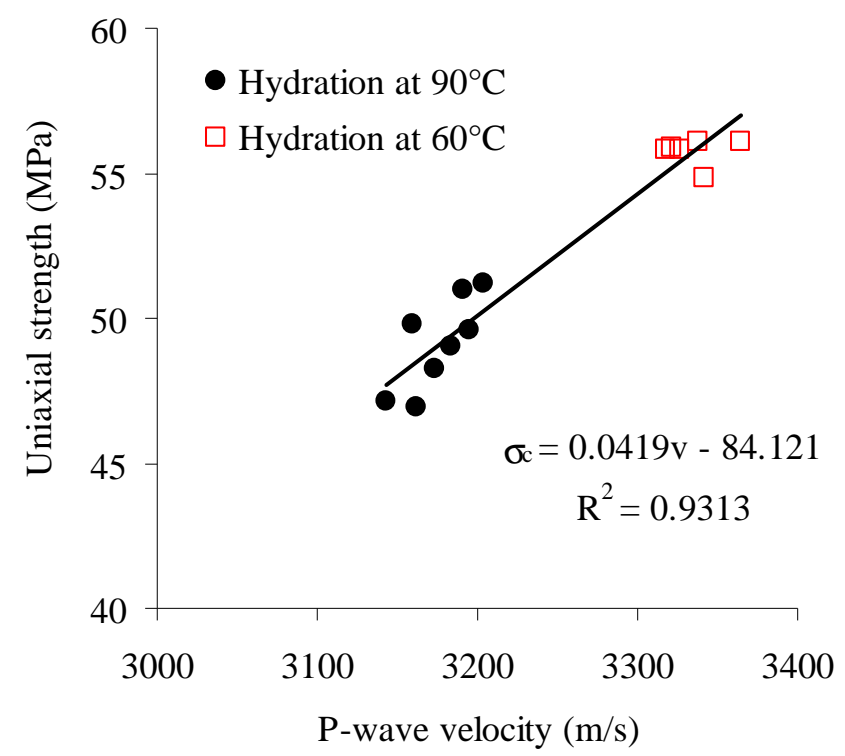

Figure 11: Uniaxial strength versus $\mathrm{P}$-wave velocity for cement pastes hydrated at $60^{\circ} \mathrm{C}$ and $90^{\circ} \mathrm{C}$ 


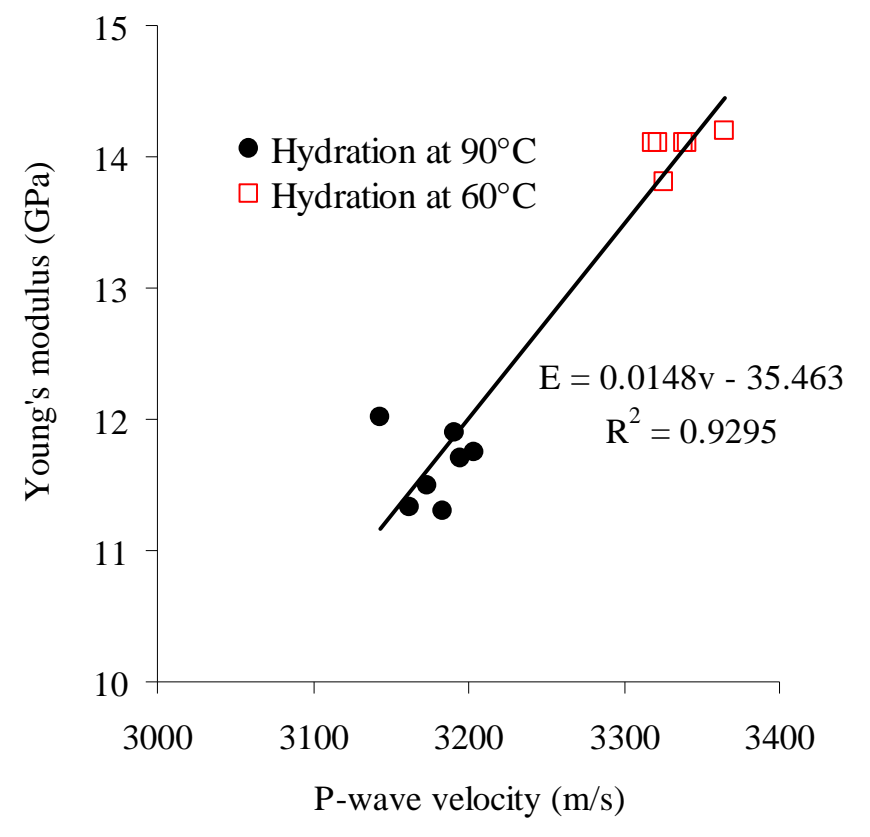

Figure 12 : Young's modulus versus $P$-wave velocity for cement pastes hydrated at $60^{\circ} \mathrm{C}$ and $90^{\circ} \mathrm{C}$ 


\section{Aknowledgements}

The authors gratefully acknowledge TOTAL for supporting this research. They wish also to thank François Martineau (IFSTTAR) and Gregory Galdiolo (TOTAL) for their assistance in the testing programme.

\section{References}

[1] S. Ghabezloo, J. Sulem, S. Guedon, F. Martineau, J. Saint-Marc, Poromechanical of hardened cement paste under isotropic loading. Cement and Concrete Research 38(12) (2008) 1424-1437.

[2] S. Ghabezloo, Comportement thermo-poro-mécanique d'un ciment pétrolier, $\mathrm{PhD}$ Thesis, Ecole Nationale des Ponts et Chaussées, France, 2008.

[3] S. Ghabezloo, J. Sulem, J. Saint-Marc. The effect of undrained heating on a fluidsaturated hardened cement paste. Cement and Concrete Research 39(1) (2009) 54-64.

[4] S. Ghabezloo, J. Sulem, J. Saint-Marc, Evaluation of a permeability-porosity relationship in a low-permeability creeping material using a single transient test, International journal of Rock Mechanics and Mining Sciences, 46(4) (2009) 761-768.

[5] F.-J. Ulm, G. Constantinides, F.H. Heukamp, Is concrete a poromechanics material? -A multiscale investigation of poroelastic properties, Materials and Structures 37 (265) (2004) 43-58.

[6] S. Ghabezloo, Association of macroscopic laboratory testing and micromechanics modelling for the evaluation of the poroelastic parameters of a hardened cement paste, Cement and Concrete research, 40(8) (2009), 1197-1210.

[7] S. Ghabezloo, Micromechanics analysis of thermal expansion and thermal pressurization of a hardened cement paste, Cement and Concrete Research 41(5) (2011) 520-532.

[8] S. Ghabezloo. Effect of the variations of clinker composition on the poroelastic properties of hardened class G cement paste, Cement and Concrete Research (2011), 41(8) (2011) 920-922.

[9] H. M. Jennings, Refinements to colloid model of C-S-H in cement: CM-II, Cement and Concrete Research 38 (2008) 275-289.

[10] C. Mazzotti, M. Savoia, Nonlinear creep damage model for concrete under uniaxial compression, Journal of Engineering Mechanics 129(9) 2003.

[11] R.A. Schapery, Correspondence principles and a generalized J-integral for large deformation and fracture analysis of viscoelastic media, Int. J. Fracture, 25(1) (1984) 95-223.

[12] D. Roylance, Engineering viscoelasticity, Department of Materials Science and Engineering, Massachusetts Institute of Technology (2001).

[13] Y. Abousleiman, Cheng A. H.-D., Jiang C., Roegiers J.-C., Poroviscoelastic analysis of borehole and cylinder problems, Acta Mechanica 119 (1996) 199-219.

[14] K. Velez, S. Maximilien, D. Damidot, G. Fantozzi, F. Sorrentino, Determination by nanoindentation of elastic modulus and hardness of pure constituents of Portland cement clinker, Cement and Concrete Research 31 (2001) 555-561. 
[15] J. Nemecek, Creep effects in nanoindentation of hydrated phases of cement pastes, Materials Characterization 60 (2009) 1028-1034.

[16] H. M. Jennings, P.D. Tennis, Model for the developing microstructure in Portland Cement Pastes, J. Am. Ceram. Soc 77(12) (1994) 3161-72

[17] H. M. Jennings, A model for the microstructure of calcium silicate hydrate in cement paste, Cement and Concrete Research 30 (2000) 101-116.

[18] H. M. Jennings, Colloid model of C-S-H and implications to the problem of creep and shrinkage, Materials and Structures/ Concrete Science and Engineering 37 (2004) 59-70.

[19] Jennings H.M., Thomas J.J., Gevrenov J.S., Constantinides G., Ulm F.-J., A multitechnique investigation of the nanoporosity of cement paste, Cement and Concrete Research, 37 (2007) 329-336.

[20] R. Alizadeh, J. J. Beaudoin, L. Raki, Viscoelastic nature of calcium silicate hydrate, Cement \& Concrete Composites 32 (2010) 369-376

[21] G. W. Scherer, Dynamic pressurization method for measuring permeability and modulus: I. theory. Materials and Structures 39 (2006) 1041-1057.

[22] J. J. Valenza, G. W. Scherer, Evidence of anomalous thermal expansion of water in cement paste, Cement and Concrete Research 35 (2005) 57-66.

[23] O. Bernard, F.-J. Ulm, J.T. Germaine, Volume and deviator creep of calcium-leached cement-based materials, Cement and Concrete Research 33 (2003) 1127-1136.

[24] F. Benboudjema, Modélisation des déformations différées du béton sous sollicitations biaxiales. Application aux enceintes de confinement de bâtiments réacteurs des centrales nucléaires, $\mathrm{PhD}$ Thesis, Université de Marne-La-Vallée, U.F.R. de Sciences et Technologies, France, 2002.

[25] R.F. Feldman, Helium flow and density measurement of the hydrated tricalcium silicatewater system, Cement and Concrete Research 2(1) (1972) 123-136.

[26] G.W. Scherer, J.J. Valenza, G. Simmons, New methods to measure liquid permeability in porous materials, Cem. Concr. Res. 37 (2007) 386-397.

[27] B. T. Tamtsia, J.J. Beaudoin, Basis creep of hardened cement paste. An examination of the role of water, Cement and Concrete Research 30 (2000) 1465-1475.

[28] Z.P. Bažant, A.B. Hauggaard, S. Baweja, F.-J. Ulm, Microprestress-solidification theory for concrete creep. I: Aging and drying effects. Journal of Engineering Mechanics, 123(11) (1997).

[29] P. Klug, F.H. Wittmann, Activation energy and activation volume of creep of hardened cement paste, Materials science and Engineering 15 (1974) 63-66.

[30] J. I. Escalante-Garcia, Effect of temperature on the hydration of the main clinker phases in portland cements: Part I, neat cements, Cement and Concrete Research, 28(9) (1998)1245-1257.

[31] A. Plassais, Nanoporosité, Texture et propriétés mécaniques de pâtes de ciments, $\mathrm{PhD}$ Thesis, Université Paris 6, Spécialité de Physique et Chimie des Matériaux, France, 2003.

[32] M. Cervera, R. Faria, J. Oliver, T. Prato, Numerical modelling of concrete curing, regarding hydration and temperature phenomena, Computers and Structures 80 (2002) $1511-1521$. 
[33] M. Vandamme and F.-J. Ulm, Nanogranular origin of concrete creep, Proceedings of the National Academy of Sciences of the United States of America 106(26) (2009). 